\title{
DIRECT WRITE PROCESSING FOR PHOTOVOLTAIC CELLS
}

\author{
Tanya Rivkin, Calvin Curtis, Alex Miedaner, John Perkins, Jeff Alleman and David Ginley \\ National Renewable Energy Laboratory, 1617 Cole Blvd, Golden, CO 80401
}

\begin{abstract}
Direct writing of solar cell components is an attractive processing approach. We have fabricated a $6.8 \%$ Si solar cell using silver ink based electrodes. Ohmic contact through the antireflection (AR) coating was obtained with pure $\mathrm{Ag}$ electrodes at $850^{\circ} \mathrm{C}$. We also report on highly conductive silver metallizations and initial results on direct-write TCO demonstrating a 100micron spatial resolution produced by inkjet printing.
\end{abstract}

\section{INTRODUCTION}

A key issue in developing next generation photovoltaics is the ability to develop low cost production techniques and maintain or improve device quality. Ink jet printing of metalorganic (MO) and nanoparticle based inks as precursors potentially offers the ability to deposit high quality electronic materials with the desired spatial resolution [1]. Versatility in the formulation of the liquid inks allows fine tuning of the compositions and control of doping levels of the materials produced so as to optimize the device performance.

We have previously demonstrated silver layers with conductivities near bulk that were spray-printed from solutions of $\mathrm{MO}$ precursors and from composite MO/nanoparticulate silver precursors [2]. Using composite precursors results in much greater deposition rates. In both cases high adhesion strength to $\mathrm{Si}$ and to glass substrates was obtained without employing adhesion promoters such as glass frits or metallic adhesion layers.

For direct write contacts to be useful in photovoltaics applications they must form a lowresistance ohmic contact with the underlying semiconductor through any intervening layers. This requirement is especially challenging when the contact is fabricated on top of an antireflection coating such as the typically employed $\mathrm{Si}_{3} \mathrm{~N}_{4}[3]$. In screen-printed contacts glass frits are incorporated in the $\mathrm{Ag}$ paste. These frits are believed to "burn" through the insulating layers at relatively low temperatures $\left(\sim 700{ }^{\circ} \mathrm{C}\right)$ facilitating ohmic contact between $\mathrm{Ag}$ and $\mathrm{Si}$ [4]. Analogously, nanosized glass frits could be incorporated in the Ag inks for inkjet and spray printing. In our initial experiments, however, we used pure MO-silver inks and studied the effect of high temperature annealing on contact resistance. Here we report on inkjet and spray-printed silver contacts to Si solar cells with and without $\mathrm{Si}_{3} \mathrm{~N}_{4} \mathrm{AR}$ layers.

Transparent conducting oxides (TCO) represent another key solar cell component especially for thin film solar cells. These may also be amenable to direct write processing. MO inks or colloidal nanoparticle suspensions can be developed based on known precursors for virtually all known TCO compounds. Here we also report on initial results on the direct writing of transparent conducting oxides. $\mathrm{ZnO}$ and $\mathrm{SnO}_{2}$ were successfully printed from concentrated colloidal nanoparticulate precursors. In addition, MO precursors containing both $\mathrm{In}$ and $\mathrm{Sn}$ sources were employed to directly deposit conducting ITO films.

\section{SPRAY-PRINTED CONTACTS TO Si}

Silicon substrates with a diffused $p-n$ junction, with and without a $\mathrm{Si}_{3} \mathrm{~N}_{4} \mathrm{AR}$ layer were provided by Evergreen Solar. The substrates were briefly etched in $10 \%$ aqueous $\mathrm{HF}$ prior to $\mathrm{Ag}$ deposition. $\mathrm{MO}(\mathrm{MO})$ silver inks were prepared by dissolving $2 \mathrm{~mol}(4.2 \mathrm{~g})$ of silver(hexafluoroacetylacetonate)(1,5-cyclooctadiene) $(\mathrm{Ag}(\mathrm{hfa}) \mathrm{COD})$ in $5 \mathrm{ml}$ of toluene. 1m thick $\mathrm{Ag}$ layers were spray-printed from the $\mathrm{Ag}-\mathrm{MO}$ ink onto heated substrates at $400{ }^{\circ} \mathrm{C}$ in air using a hand-held Vega 2000 airbrush. TLM grids (Figure 1) were patterned from the sprayed silver layer using photolithography and chemical etching in concentrated nitric acid.

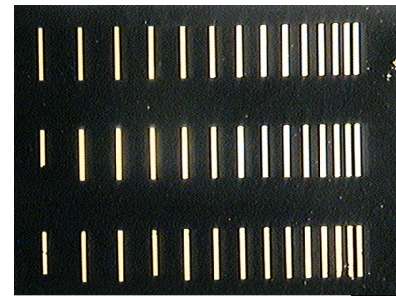

Figure 1. TLM pattern of Ag contacts fabricated on the n-type surface of Evergreen Solar material (the image is $2 x$ ).

For $\mathrm{Si}$ substrates without the AR coating, an ohmic contact with relatively low contact resistance of $0.4 \mathrm{~m} \square \cdot \mathrm{cm}^{2}$ was formed immediately during $\mathrm{Ag}$ deposition. For the substrates coated with silicon nitride, the $\mathrm{Si}_{3} \mathrm{~N}_{4}$ dielectric layer electrically insulated the asdeposited silver contacts from Si and each other. 
No current could be initiated between the contact pads by application of an external voltage up to $20 \mathrm{~V}$, above which breakdown of the insulating layer was observed.

After the initial electrical testing, the samples containing $A R$ coatings were annealed in a tube furnace in air at $600{ }^{\circ} \mathrm{C}, 750{ }^{\circ} \mathrm{C}, 800{ }^{\circ} \mathrm{C}$ and $850{ }^{\circ} \mathrm{C}$ for times ranging between 2 min and 1 hour. Due to surface tension phenomena, the originally continuous $\mathrm{Ag}$ layers broke into islands in the course of firing (SEM Figure 2). To form a continuous contact, another 2-micron thick layer of $\mathrm{Ag}$ was spray-printed on top of the already fired $\mathrm{Ag}$ pattern at $400^{\circ} \mathrm{C}$ and patterned using photoresist and etching, as before. Annealing at temperatures between $600{ }^{\circ} \mathrm{C}$ and $800{ }^{\circ} \mathrm{C}$ for a period of time from 2 minutes to 1 hour did not result in formation of ohmic contact, however the breakdown voltage for the annealed films was reduced to $1 \mathrm{~V}$.

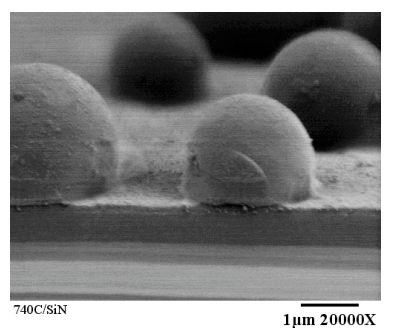

Figure 2. Ag layer breaks into isolated balls in the course of annealing at elevated temperatures

Ohmic contact between $\mathrm{Ag}$ and $\mathrm{Si}$ was obtained, however, in the samples annealed at $850{ }^{\circ} \mathrm{C}$ for times as short as 5 minutes. The best contact resistance achieved was $4 \mathrm{~m} \square \cdot \mathrm{cm}^{2}$. Following the contact resistance measurement, the $\mathrm{Ag}$ layer was removed by a prolonged etch in nitric acid, revealing the surface of the substrate under the contact. The signs of the interaction between the substrate and $\mathrm{Ag}$ layer were evident by microscopic examination (Figure 3).

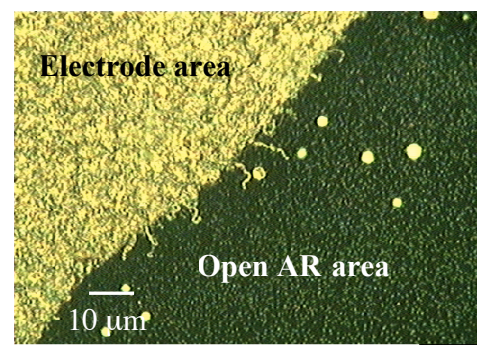

Figure 3. Optical micrograph of $\mathrm{Ag}$ printed on $\mathrm{Si}_{3} \mathrm{~N}_{4}$-coated $\mathrm{Si}$, annealed at $850^{\circ} \mathrm{C}$ and then etched, showing that the ink derived $\mathrm{Ag}$ burned through the AR coating.

An experimental $1 \mathrm{~cm}^{2}$ solar cell was prepared with spray-printed $\mathrm{Ag}$ contacts. The $\mathrm{Ag}$ grids were fabricated in a similar fashion as the
TLM patters described above (Figure 4). The back Al contact ( $1 \square \mathrm{m}$ thick) was deposited by ebeam evaporation after the first $\mathrm{Ag}$ grid was fabricated and prior to the high-temperature annealing step. The front and the back contacts were co-fired at $850{ }^{\circ} \mathrm{C}$ for $\sim 10$ minutes.

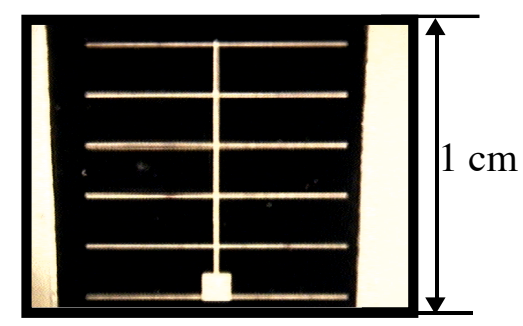

Figure 4. Si solar cell fabricated with sprayprinted Ag burned through the silicon nitride layer

This resulted in simultaneous alloying and ohmic contact formation of the front and the back contacts with Si. Again, the Ag layer broke into isolated islands in the course of the annealing. A second Ag layer was spray-deposited and patterned over the original grid in order to provide continuous front contact. The performance parameters of the fabricated cell are enumerated in the Table 1.

Table 1. The performance parameters of the cell with spray-printed front contacts.

\begin{tabular}{|l|l|}
\hline Voc & $0.5476 \mathrm{~V}$ \\
\hline Jsc & $26.762 \mathrm{~mA} / \mathrm{cm}^{2}$ \\
\hline FF & $46.16 \%$ \\
\hline Eff & $6.76 \%$ \\
\hline
\end{tabular}

The low fill factor (FF) is probably due to high series resistance resulting from insufficient thickness of the front and back contact metallizations. This initial experiment demonstrates the feasibility of printed $\mathrm{Ag}$ contacts on Si solar cells and shows significantly that the metal-organic ink is capable of burning through the AR coating to form a low-resistance ohmic contact.

\section{INKJET-PRINTED SILVER ELECTRODES}

The MO Ag inks were printed using a Microfab drop-on-demand inkjet printer. In this system the drops are stimulated at the tip of a glass capillary by an acoustic wave produced by a piezoelectric actuator. The frequency, and to some degree, the volume of the generated drops, can be controlled by an operator. Such flexibility in printing parameters helps in controlling deposition rate and resolution of a printed line. When printing parameters are optimized, the most important factors that limit the line resolution are the size of the drop-generating 
orifice and the wetting properties of the ink on the surface of a substrate. Our MO Ag inks (Ag(hfa)COD in organic solvents) were printed on glass, $\mathrm{Si}$ and $\mathrm{Si}_{3} \mathrm{~N}_{4}$ coated $\mathrm{Si}$ substrates using a $50 \square \mathrm{m}$ jet. The best line resolution $(100 \square \mathrm{m})$ (Figure 5) was achieved with butanol-based ink (highest viscosity solvent) printed on heated (120 ${ }^{0}$ ) glass substrates.

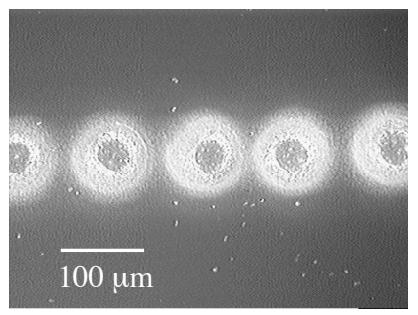

Figure 5. Individual $100 \square \mathrm{m} \mathrm{Ag}$ drops printed on glass at $120^{\circ} \mathrm{C}$ with the Microfab inkjet printer using $\mathrm{Ag}(\mathrm{hfa})(\mathrm{COD}) /$ butanol ink.

The printed precursor lines turned into pure Ag during the following annealing step at $250{ }^{\circ} \mathrm{C}$ in air. The toluene-based inks demonstrate lower resolution but may be printed at temperatures above that required to decompose the precursor, thus directly producing Ag patterns without the need for postdeposition annealing (Figure 6).

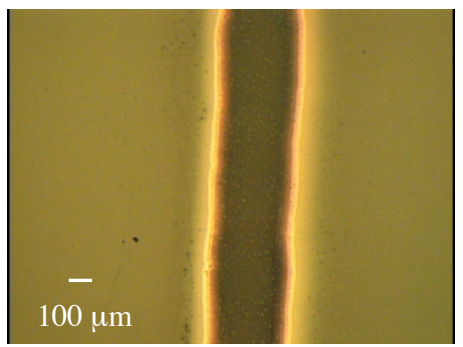

Figure 6. $300 \square \mathrm{m}$ wide $\mathrm{Ag}$ line printed on glass at $200{ }^{\circ} \mathrm{C}$ with the Microfab inkjet printer using $\mathrm{Ag}(\mathrm{hfa})(\mathrm{COD}) /$ toluene ink.

The homogeneous MO inks are very compatible with the inkjet-printers. High quality conducting lines are produced with $\mathrm{MO}$ inks, but the deposition rates are rather low $(300 \AA-500 \AA$ per pass). Thus we are developing alternate precursors that are capable of higher deposition rates. Two approaches are currently being evaluated. One is using alternate MO precursors capable of higher solubility in suitable solvents. Second is using concentrated suspensions of $\mathrm{Ag}$ nanoparticles.

Applying the former approach we have attained concentrations of up to $8 \mathrm{M}$ of $\mathrm{Ag}$ with a Ag-trifluoroacetate precursor in water. This is four times higher concentration than that attained for (silver-(hexafluoroacetylacetonate) $(1,5$ - cyclooctadiene) and should lead to deposition rates up to $2000 \AA$ per pass. The new concentrated ink was printable by inkjet and demonstrated pure silver deposits upon decomposition in air at $250{ }^{\circ} \mathrm{C}$. Poor wetting of the substrate by the ink in our original printing experiments led to non-uniform distribution of the printed precursor making it difficult to evaluate the average thickness of the Ag deposit. Followon work will focus on optimizing ink rheological properties and the substrate surface to produce uniform layers.

Key to the latter approach is stabilizing concentrated Ag suspensions. A certain degree of agglomeration would be tolerable, however aggregates with sizes greater than 5 microns would constrict the flow of the precursor through the orifice of the inkjet reducing line resolution and increasing the chance for clogging of the orifice of the inkjet. Surface stabilization of the nanoparticles with organic surfactants may alleviate the agglomeration through stabilizing the suspension of the nanoparticles. Developing stabilized nanoparticle inks has a potential to result in much greater deposition rates than the highest possible for $\mathrm{MO}$ precursors. Initial results with composite nanoparticulate/MO precursors of $\mathrm{Ag}$ have shown that it is possible to attain up to $10 \mu \mathrm{m}$ thick layers with conductivities within factor of two of that for bulk Ag.

\section{INKJET-PRINTED TCO}

Water-based colloids of $\mathrm{ZnO}$ and $\mathrm{SnO}_{2}$ from NYACOL were printed on Pyrex glass substrates at $125{ }^{\circ} \mathrm{C}$ and $800 \mathrm{~Hz}$ deposition rate (800 drops per second). Narrow (100 $\square \mathrm{m})$ and thick (5 $\square \mathrm{m})$ lines were printed in a single pass (Figure 7). Asprinted pure $\mathrm{ZnO}$ and $\mathrm{SnO}_{2}$ particulate precursors are not conductive. Annealing in a reducing atmosphere as well as introducing doping elements (such as $\mathrm{Al}$ for $\mathrm{ZnO}$ and $\mathrm{F}$ for $\mathrm{SnO}_{2}$ ) via intermixed $\mathrm{MO}$ compounds will be used to control the doping level in the printed oxides. In this approach, small amounts of water-soluble MO precursors are added to the colloidal suspension. The MOD reagent is uniformly dispersed in the colloid providing a uniform supply of doping elements. When printed and annealed above the decomposition temperature of the MO precursor the dopant is free to diffuse into the oxide particles. Also during the anneal the individual particles sinter together in a conducting continuum. For nanoparticles this occurs at lower temperatures than normal because of surface energy considerations. Both reducing anneal and doping via $\mathrm{MO}$ will increase carrier concentrations and thus improve conductivity of the printed TCOs.

Conducting ITO films were also printed from a commercial (CHEMAT) MO ITO precursor in hexanes. $100 \square \mathrm{m}$ lines of the precursor were 
printed at $50-75{ }^{\circ} \mathrm{C}$ on Pyrex glass slides. Rectangular patterns of the precursor were produced by printing individual lines with 20 micron overlap.

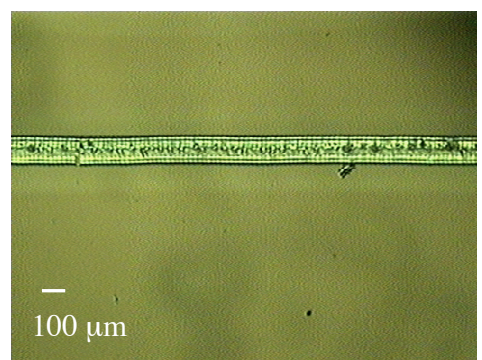

Figure 7. $100 \square \mathrm{m} \mathrm{SnO} 2$ line printed on glass at $125^{\circ} \mathrm{C}$ with the Microfab inkjet printer using NYACOL colloidal tin oxide precursor

The printed precursor patterns were decomposed by annealing in air at $300{ }^{\circ} \mathrm{C}$. The solid and transparent $1000 \AA$ thick films thus produced had a resistivity of $300 \mathrm{Ohm} \cdot \mathrm{cm}$. Annealing in air at $700{ }^{0} \mathrm{C}$ significantly improved the resistivity reducing it to $0.03 \mathrm{Ohm} \cdot \mathrm{cm}$. A further improvement in resistivity down to 0.004 $\mathrm{Ohm} \bullet \mathrm{cm}$ was achieved with a one-hour reducing anneal in argon at $400{ }^{\circ} \mathrm{C}$.

With these initial experiments, we demonstrated that low resistivity transparent ITO patterns can be inkjet printed from MO precursors. Also high deposition rates and good resolution were obtained for colloidal TCO precursors.

\section{SUMMARY}

Metal contacts and transparent conducting oxide layers were printed from $\mathrm{MO}$ and nanoparticulate precursors. High quality materials can be achieved by printing liquid precursors under atmospheric conditions. Using direct write techniques such as inkjet printing may eliminate expensive steps of vacuum deposition, photolithography and etching, significantly reducing the cost of solar cell fabrication. In addition, the ability to control the composition of the precursors in real time can lead to tremendous flexibility in controlling the conductivity and doping levels spatially. Ink formulation and process optimization are underway to produce higher quality materials and more efficient devices by direct write techniques.

\section{REFERENCE}

1. K.F. Teng, R.W.V., Metallization of Solar Cells with Ink Jet Printing and Silver Metallo-Organic Inks. IEEE

Transactions on Components, Hybrids, and Manufacturing Technology, 1988. 11(3): p. 291-297.

$2 . \quad$ C.J. Curtis, D.L.S., A. Miedaner, J. Alleman, T. Rivkin, J.D. Perkins and D.S.Ginley. Spray and inkjet printing of hybrid nanoparticle-metal-organic inks for $\mathrm{Ag}$ and $\mathrm{Cu}$ metallizations. in Materials Research Society Symposium. 2002.

3. Duerinckx, F.S., J., Defect passivation of industrial multicrystalline solar cells based on PECVD silicon nitride. Solar Energy Materials and Solar Cells, April, 2002. 72(1-4).

4. Nijs, J.D., E.; Szlufcik, J.; Poortmans, J.; Frisson, L.; De Clercq, K.; Mertens, R.; Van Overstraeten, R.; Ghannam, M., Recent improvements in the screenprinting technology and comparison with the buried contact technology by $2 D$-simulation. Solar Energy Materials and Solar Cells, June, 1996. 41-42: p. 101-117. 